\title{
AN INSIGHT INTO PARENTAL ATTITUDES ON ROAD SAFETY MEASURES
}

Hendaus $\mathrm{MA}^{1,2,3}$, Wassef $\mathrm{R}^{1}$, Mansour $\mathrm{M}^{1}$, Abdel-Karim $\mathrm{T}^{1}$, Alhammadi $\mathrm{A}^{1,2,3}$

(1) Hamad Medical Corporation. Doha, Qatar (2) Sidra Medical \& Research Center . Doha, Qatar (3) Weill Cornell Medical College in Qatar

\section{5 \\ Background \&}

\section{Aims}

Lack of knowledge of the prevalence of morbidity and mortality due to road danger might be a major cause of why parents are not robustly involved in road safety decision making. The aim of the study was to explore parental knowledge of the morbidity and mortality related to road danger in the State of Qatar.

\section{Materials \& Methods}

A cross-sectional prospective study was conducted at Hamad Medical Corporation.

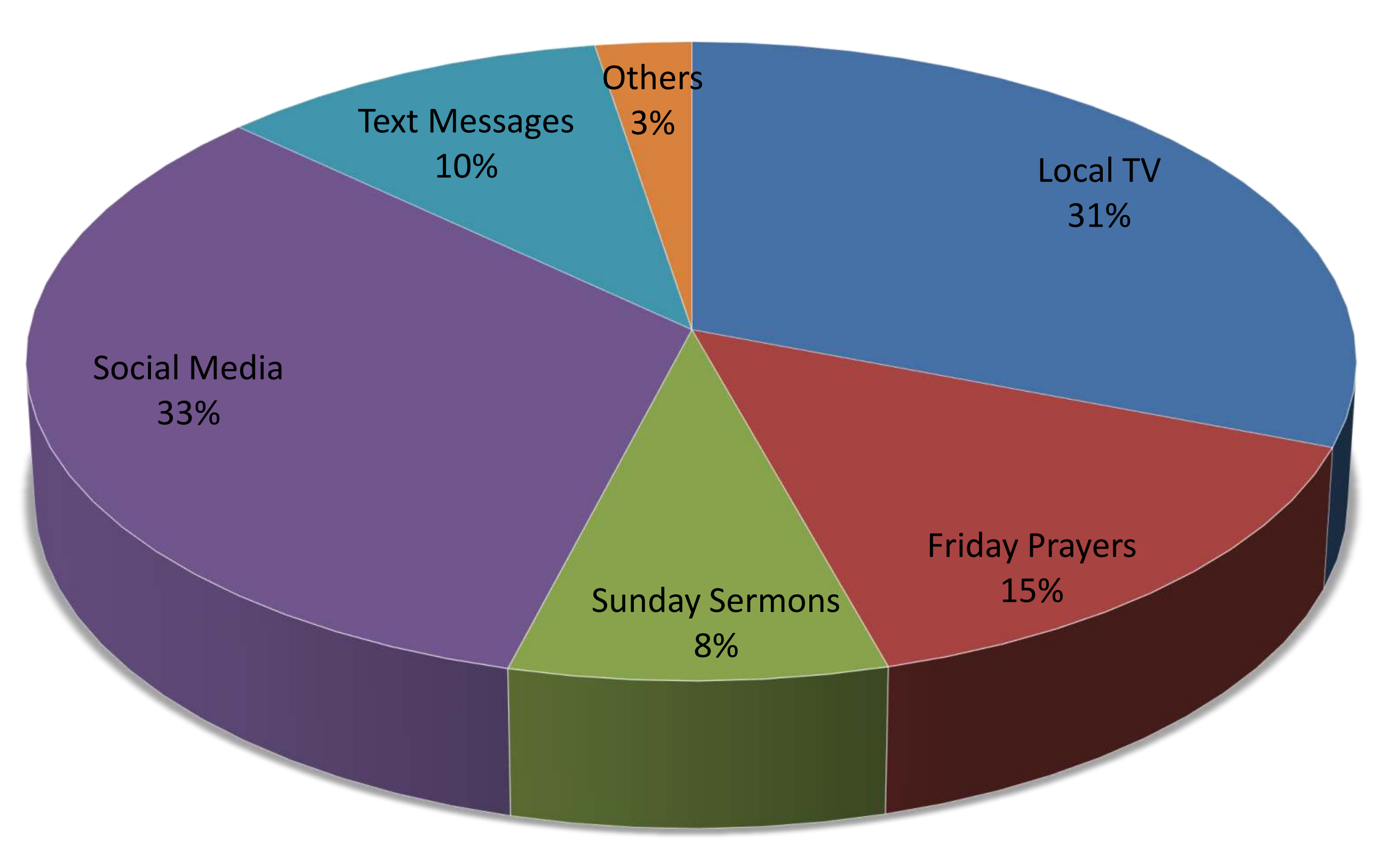

Furthermore, around $80 \%$ felt that billboards on the side of the road with messages that "Your Family is waiting for you" will deter them from speeding. Role modeling was also assessed, and it showed that $85 \%$ of parents believed that the most effective way in teaching children and young people to use roads in a safe way, is to always provide a positive role model when using the roads.

\section{Results}

300 questionnaires were completed, with no rejection rate. Interestingly $63 \%$ of families were familiar with the prevalence of car accidents in Qatar, while less than one half were familiar with the rate of mortality and disability that arises from car crashes. Moreover, 1 in 2 persons felt that keeping crashed cars on the side of the road is a good idea to prevent speeding.

\section{Conclusion}

A large proportion of residents in the State of Qatar perceive that children are not safe while commuting in roads. Social media, a space where most of our community inhabit, seems to be the best setting to target our people. We will share our data with the ministries of internal affairs, endowment and guidance to assist to launch campaigns using specific road safety messages.

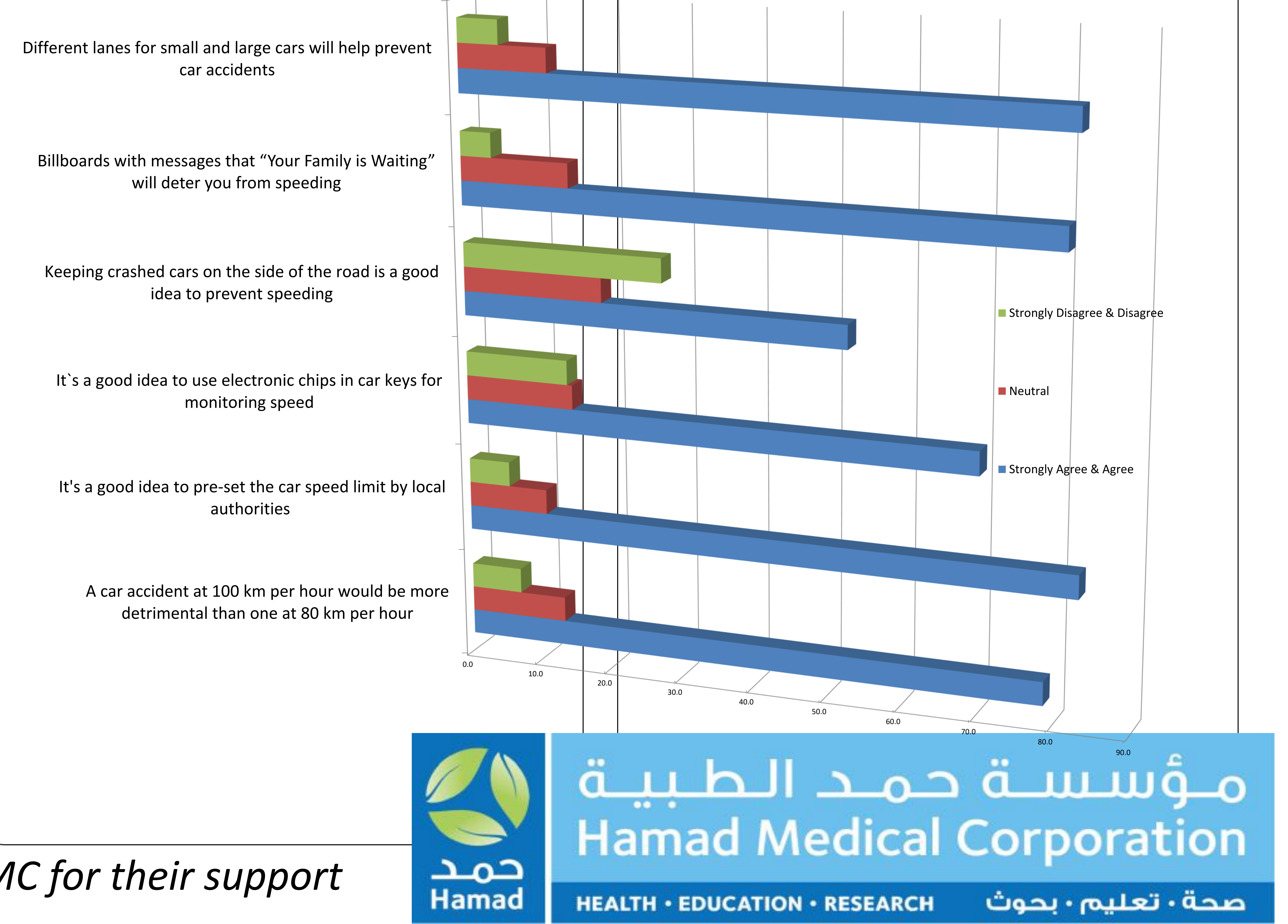

